\title{
Characteristics of Missed Simultaneous Gastric Lesions Based on Double-Check Analysis of the Endoscopic Image
}

\author{
Eun Jeong Gong, Jeong Hoon Lee, Kyoungwon Jung, Charles J. Cho, Hee Kyong Na, Ji Yong Ahn, Kee Wook Jung, Do Hoon Kim, \\ Kee Don Choi, Ho June Song, Gin Hyug Lee, Hwoon-Yong Jung and Jin-Ho Kim \\ Department of Gastroenterology, Asan Medical Center, University of Ulsan College of Medicine, Seoul, Korea
}

Background/Aims: The detection of multifocal lesions is important for the successful management of gastric neoplasms. We investigated the characteristics of missed simultaneous lesions and the reason for the missed diagnoses.

Methods: A total of 140 patients who underwent repeat endoscopy before endoscopic resection between June 2013 and June 2014 were retrospectively reviewed. We classified simultaneous lesions into three groups based on a review of earlier images: group 1, no images of the location of simultaneous lesions were taken; group 2, no corresponding lesion was evident in the previous images; and group 3, simultaneous lesions were visible in the earlier images but a biopsy was not performed.

Results: Simultaneous lesions were found in 12 patients (8.6\%) with 13 lesions, comprising 10 dysplasia (76.9\%) and three adenocarcinoma (23.1\%). Regarding the reasons for missed diagnoses, seven lesions (53.8\%) were classified as group 3, five (38.5\%) as group 1 , and the remaining lesion $(7.7 \%)$ as group 2 . There were no significant differences in the characteristics of the patients with and without simultaneous lesions.

Conclusions: Lesions disregarded or unnoticed during endoscopic examination were the main reason for missed diagnosis of simultaneous lesions. Endoscopists should consider the possibility of simultaneous lesions and attempt to meticulously evaluate the entire gastric mucosa. Clin Endosc 2017;50:261-269

Key Words: Endoscopy; Stomach neoplasms; Quality

\section{INTRODUCTION}

Endoscopic resection is regarded as the standard treatment for gastric neoplasms because of its minimal invasiveness and favorable outcomes. ${ }^{1,2}$ With effective endoscopic surveillance, gastric neoplasms are increasingly diagnosed at an early stage and are possible candidates for endoscopic resection. ${ }^{3}$

Endoscopic examination with biopsy is the gold standard for the diagnosis of gastric neoplasm. However, neoplastic

Received: April 16, 2016 Revised: July 3, 2016

Accepted: July 27, 2016

Correspondence: Jeong Hoon Lee

Department of Gastroenterology, Asan Digestive Disease Research Institute, Asan Medical Center, University of Ulsan College of Medicine, 88 Olympic-ro 43-gil, Songpa-gu, Seoul 05505, Korea

Tel: +82-2-3010-5678, Fax: +82-2-476-0824, E-mail: jhlee.gi@amc.seoul.kr

(cc) This is an Open Access article distributed under the terms of the Creative Commons Attribution Non-Commercial License (http://creativecommons.org/ licenses/by-nc/3.0) which permits unrestricted non-commercial use, distribution, and reproduction in any medium, provided the original work is properly cited. lesions can be missed during endoscopic examination. ${ }^{4,5}$ In patients with previously diagnosed gastric neoplasm, if the information from the referring center is insufficient, or a definite target for treatment needs to be identified, repeat endoscopy is performed before deciding on the treatment strategy. Moreover, during endoscopic resection, endoscopists occasionally detect an additional lesion that was not diagnosed in previous examinations, and this may lead to unscheduled procedures or modification of the therapeutic plan. Accurate detection of multifocal lesions before endoscopic resection is, therefore, necessary for the successful management of gastric neoplasms.

The prevalence of synchronous lesions after endoscopic resection has been reported to be $2.0 \%$ to $11.6 \%{ }^{6-8}$ The majority of studies reporting the prevalence and diagnosis of synchronous gastric neoplasms have focused on the prevalence after previous endoscopic examinations that were performed within a certain period of time. ${ }^{6,810}$ Recently, one such study suggested 
that one-third of those lesions could have been detected during the previous endoscopic examinations. ${ }^{7}$ We investigated the characteristics of simultaneous lesions missed before endoscopic resection for gastric neoplasm, aimed primarily at elucidating the reason for missed diagnoses.

\section{MATERIALS AND METHODS}

Patients referred to Asan Medical Center for further evaluation of gastric neoplasm and who underwent repeat endoscopy between June 2013 and June 2014 were eligible for this study. During the study period, a total of 153 patients with gastric neoplasms were consecutively referred to a single physician (JHL) at our center. Of these patients, five whose medical records and endoscopic images were missing and eight who did not undergo repeat endoscopy were excluded; the remaining 140 cases were analyzed (Fig. 1). The study protocol was approved by the Institutional Review Board of Asan Medical Center.

Repeat esophagogastroduodenoscopy was performed before endoscopic resection to confirm the location of the index neoplasm and to investigate the presence of any additional lesions. Endoscopic examinations were performed using a CV260SL system (Olympus, Tokyo, Japan) with a high-resolution GIF-H260 or GIF-H260Z endoscope (Olympus). In addition to conventional white-light endoscopy, narrow band imaging or chromoendoscopy was used during the examination to further characterize the lesions. Biopsy specimens were obtained from all suspicious lesions for histological confirmation.

Clinicopathologic features, including tumor factors and procedure-related factors, were retrospectively reviewed from medical records. We evaluated the endoscopic images taken at the referring center and classified the image quality as poor, fair, or good (Fig. 2). If there was a blurring of images or disturbances such as gastric content or unwashed mucus, the

153 patients with gastric neoplasm

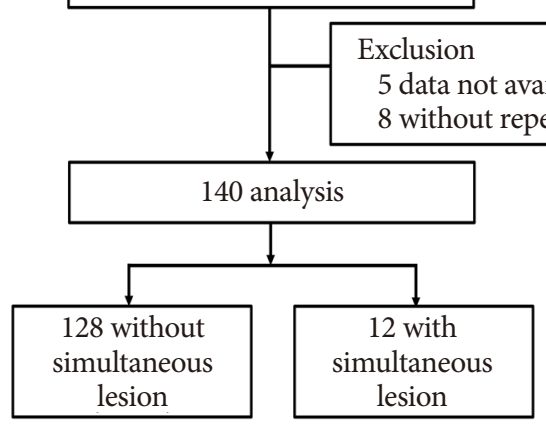

Fig. 1. Flowchart of the study. image was considered poor. If the gastric mucosa was clear and well-visualized, the image was considered good. If most images could be interpreted but some portion of the gastric mucosa was not clearly visualized, the image was considered fair. Valid images were defined as images of an area other than the primary lesion that had previously been diagnosed as gastric neoplasm. The total number of images of the scanned gastric mucosa and the number of valid images were counted.

Simultaneous lesions were defined as lesions detected for the first time on repeat endoscopy. They were classified into three groups based on a comparison of the endoscopic images obtained in the earlier and repeat examinations: group 1, no available previous image of the area where the simultaneous lesion was detected; group 2, an image of the area where the simultaneous lesion was located was available but the corresponding lesion was not clearly visible in the earlier images; and group 3, the simultaneous lesion was visible in the earlier images but no biopsy was performed at the time. Representative cases from groups 2 and 3 are shown in Fig. 3. The descriptions of gastric neoplasm, including the location and macroscopic types, were based on the classification proposed by the Japanese Gastric Cancer Association. ${ }^{11}$

\section{Statistical analysis}

Differences between clinical characteristics were determined using Student $t$-test, the chi-square test, Mann-Whitney $U$-test, or Fisher exact test as appropriate. The paired $t$-test or Wilcoxon signed-rank test was used to analyze paired data. SPSS version 18.0 (SPSS Inc., Chicago, IL, USA) was used for all statistical analyses, and a $p<0.05$ was considered significant.

\section{RESULTS}

\section{Characteristics of patients who underwent repeat endoscopy}

A total of 140 patients who underwent repeat endoscopy before endoscopic resection were analyzed. The median patient age was 62 years (range, 35 to 85 ) and the male to female ratio was 3:1. According to the pathological diagnosis of the primary lesion, 37 lesions (26.4\%) were low-grade dysplasia, 13 (9.3\%) were high-grade dysplasia, and 90 (64.3\%) were adenocarcinoma. Most of the primary lesions were located in the lower third of the stomach. Macroscopically, 66 lesions (47.1\%) were elevated, 25 (17.9\%) were flat, and $49(35.0 \%)$ were depressed. The median tumor size was $14 \mathrm{~mm}$ (range, 2 to 78). There were no significant differences in baseline characteristics between patients with and without simultaneous lesions (Table 1). ${ }^{12}$ 

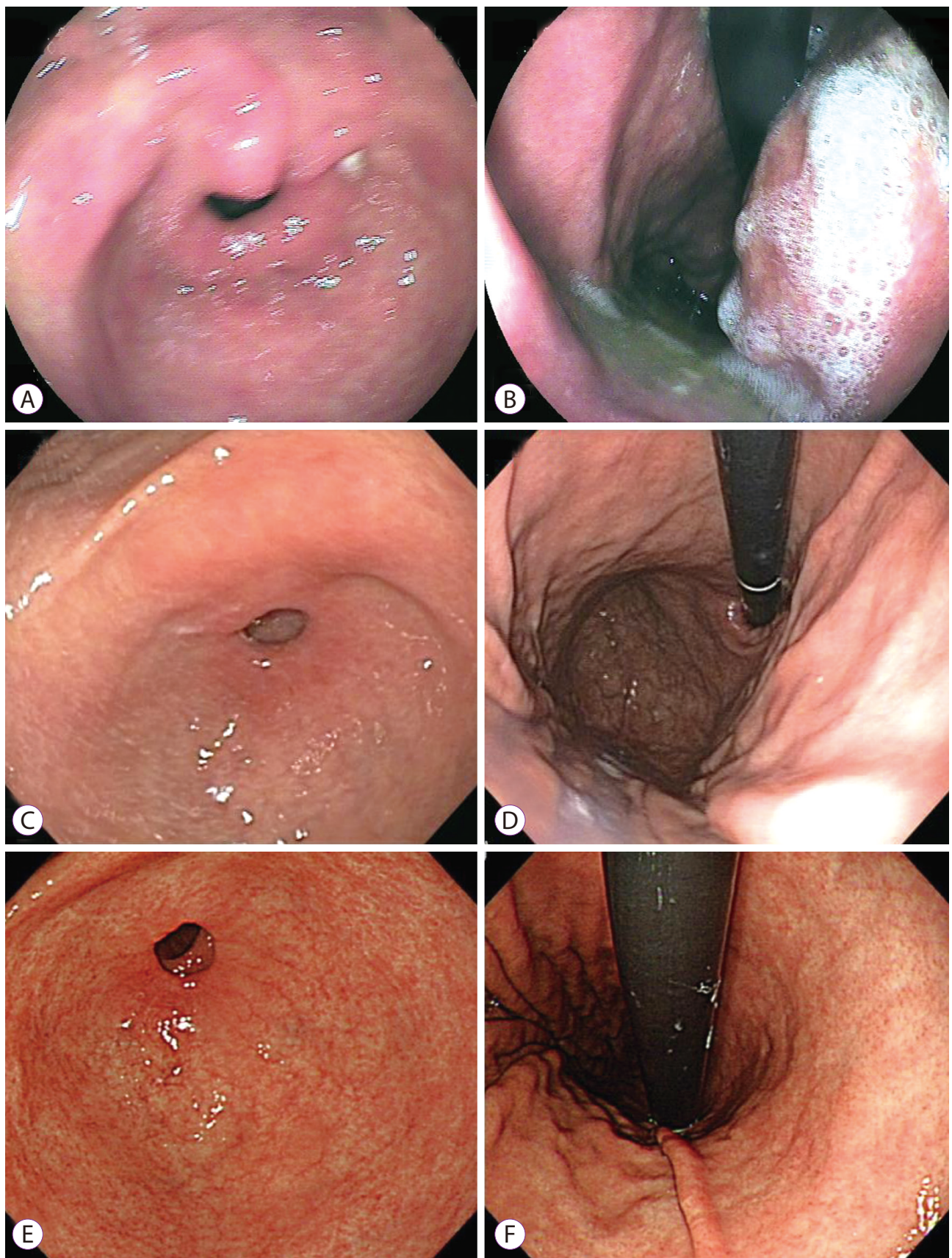

Fig. 2. Representative images of each level of quality. (A, B) Poor: the image of the antrum is blurry and more than half of the gastric mucosa is covered with mucus and gastric contents. (C, D) Fair: the image of the gastric body is relatively clear, but the antrum has a hazy appearance. (E, F) Good: all images are clear and the gastric mucosa is well-visualized.

\section{Characteristics of missed simultaneous lesions}

Among the study population, simultaneous lesions were found in 12 patients (8.6\%) with 13 lesions. According to the pathological diagnosis of the simultaneous lesions, $10(76.9 \%)$ were low-grade dysplasia and three (23.1\%) were adenocarcinoma (Table 2). Most simultaneous lesions were in the lower third of the stomach and the median tumor size was $18 \mathrm{~mm}$ (range, 7 to 54). Regarding the reasons for missed diagnosis, seven of the simultaneous lesions (53.8\%) were classified as group 3, five (38.5\%) as group 1 , and the remaining lesions $(7.7 \%)$ as group 2. Detailed characteristics of these lesions are shown in Table 3.

Treatments for simultaneous lesions were as follows (Table 3): all three adenocarcinomas and the seven low-grade dysplasias were treated with endoscopic resection and were curative; two low-grade dysplasias were ablated using argon plasma 


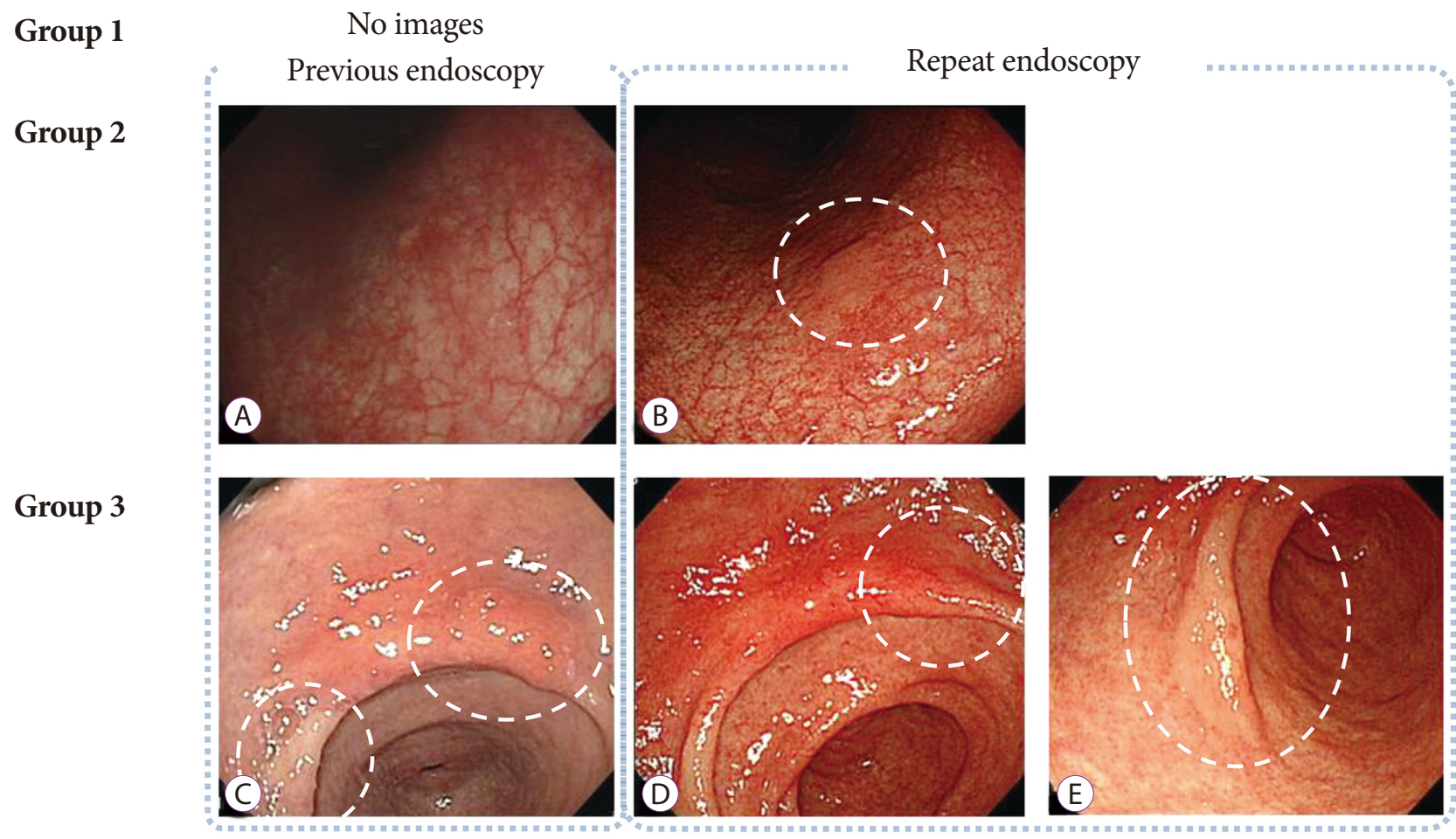

Fig. 3. Classification of simultaneous lesions detected on repeat endoscopy. (A, B) When images of the location where the simultaneous lesion was detected were available but the corresponding lesion was not evident at the time of the previous examination, the case was classified as group 2. (C-E) When images of a simultaneous lesion were available but the lesion was not biopsied, the case was classified as group 3. (A) The dysplastic lesion was not clearly defined at the time of previous endoscopy. (B) Repeat endoscopy showed a flat elevated lesion with a slightly whitish color on the lesser curvature of the midbody. (C) Endoscopic image acquired during prior endoscopic examination showing a flat hyperemic lesion in the lesser curvature of the antrum and a whitish discolored lesion in the antrum anterior wall; however, the latter lesion was not biopsied. (D, E) Repeat endoscopy with biopsy led to a diagnosis of low-grade dysplasia; the two lesions were treated simultaneously using endoscopic resection.

coagulation; the remaining patient with low-grade dysplasia (no. 2) was simply observed because the biopsied lesion was not definite in the follow-up endoscopic examination.

Regarding the treatment of the primary lesions, endoscopic resection was non-curative in two patients: one of these two patients had lymphovascular invasion (no. 4) and the other had a positive resection margin (no. 10). Histopathological examination of the resected specimens on subsequent surgery showed neither residual tumor nor lymph node metastasis.

\section{Comparison of procedure-related factors}

The institutions where the initial endoscopic examinations were performed included primary clinics in 50 cases (35.7\%), secondary or tertiary care centers in 66 cases $(47.1 \%)$, and healthcare screening centers in 18 cases (12.9\%). The quality of the images was classified as fair or good for 126 patients (90.0\%). When comparing factors between patients with and without simultaneous lesions, the type of referring center, quality of image, number of images taken, and the procedure times did not differ between the two groups (Table 4). The re- peat endoscopy involved significantly more images and longer procedure times than the original endoscopy. However, when analyzing the absolute differences in the number of images and the procedure times, there were no differences between the two endoscopic procedures (Table 5).

\section{DISCUSSION}

In the present study, we investigated the characteristics of missed simultaneous lesions before endoscopic resection for gastric neoplasm, with the primary aim of clarifying the reason for missed diagnoses. In the population studies, simultaneous lesions were detected in $8.6 \%$ of patients, and lesions disregarded or unnoticed during the original examination were the major reasons for missed diagnosis. Procedure-related factors such as procedure time did not differ in patients with and without simultaneous lesions.

Endoscopic resection of gastric neoplasm leaves most of the normal gastric mucosa intact and further neoplasms can be present or arise in the remaining gastric mucosa. Additional 
Table 1. Baseline Characteristics of Patients with Gastric Neoplasm

\begin{tabular}{|c|c|c|c|c|}
\hline Characteristic & Total $(n=140)$ & $\begin{array}{c}\text { Without simultaneous } \\
\text { lesion }(n=128)\end{array}$ & $\begin{array}{l}\text { With simultaneous } \\
\text { lesion }(n=12)\end{array}$ & $p$-value \\
\hline Age, yr & $62(35-85)$ & $62(35-85)$ & $65(51-78)$ & 0.134 \\
\hline Male sex & $105(75.0)$ & $97(75.8)$ & $8(66.7)$ & 0.495 \\
\hline Helicobacter pylori infection & $105(75.0)$ & $94(73.4)$ & $11(91.7)$ & 0.294 \\
\hline Gastric atrophy $^{\text {a) }}$ & & & & 0.755 \\
\hline Closed-type & $76(54.3)$ & $70(54.7)$ & $6(50.0)$ & \\
\hline Open-type & $64(45.7)$ & $58(45.3)$ & $6(50.0)$ & \\
\hline \multicolumn{5}{|c|}{ Characteristics of the primary lesion } \\
\hline Location in stomach & & & & 0.497 \\
\hline Upper & $16(11.4)$ & $16(12.5)$ & 0 & \\
\hline Middle & $38(27.1)$ & $35(27.3)$ & $3(25.0)$ & \\
\hline Lower & $86(61.4)$ & $77(60.2)$ & $9(75.0)$ & \\
\hline Histological diagnosis & & & & 0.575 \\
\hline Low-grade dysplasia & $37(26.4)$ & $34(26.6)$ & $3(25.0)$ & \\
\hline High-grade dysplasia & $13(9.3)$ & $11(8.6)$ & $2(16.7)$ & \\
\hline Adenocarcinoma & $90(64.3)$ & $83(64.8)$ & $7(58.3)$ & \\
\hline Differentiation $^{\text {b) }}$ & & & & 0.590 \\
\hline Differentiated & $76(84.4)$ & $69(83.1)$ & $7(100.0)$ & \\
\hline Undifferentiated & $14(15.6)$ & $14(16.9)$ & 0 & \\
\hline Gross morphology & & & & 0.341 \\
\hline Elevated & $66(47.1)$ & $58(45.3)$ & $8(66.7)$ & \\
\hline Flat & $25(17.9)$ & $23(18.0)$ & $2(16.7)$ & \\
\hline Depressed & $49(35.0)$ & $47(36.7)$ & $2(16.7)$ & \\
\hline Size, $\mathrm{mm}$ & $14(2-78)$ & $14(2-78)$ & $18(7-54)$ & 0.183 \\
\hline
\end{tabular}

Values are presented as median (range) or number (\%).

${ }^{a)}$ Gastric atrophy: based on the classification proposed by Kimura and Takemoto ${ }^{12}$; b) Regarding the cancer patients (differentiated, well or moderately differentiated; undifferentiated, poorly differentiated or signet ring cell carcinoma).

Table 2. Pathological Diagnoses of Patients with Simultaneous Lesions Revealed by Repeat Endoscopy

\begin{tabular}{lcccc}
\hline \multirow{2}{*}{ Primary lesion } & \multicolumn{3}{c}{ Simultaneous lesion } & Total \\
\cline { 2 - 4 } & Low-grade dysplasia & High-grade dysplasia & Carcinoma & 3 \\
Low grade dysplasia & 3 & 0 & 0 & 2 \\
High grade dysplasia & 2 & 0 & 0 & 8 \\
Carcinoma & $5^{\text {a) }}$ & 0 & 3 & 13 \\
Total & 10 & 0 & 3 & 3 \\
\hline
\end{tabular}

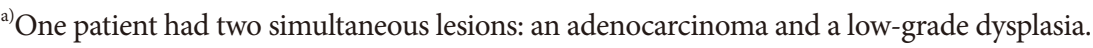

treatment such as repeated endoscopic resection or gastrectomy for missed gastric neoplasm will result in increased cost, and therefore, efforts should be made to detect simultaneous lesions before endoscopic resection once a gastric neoplasm has been diagnosed. The prevalence of missed synchronous lesions has been variously reported, and several factors including pathologic diagnosis of the primary lesion (adenoma), the number of biopsies taken, and small lesion size have been recognized as risk factors for failure to detect additional lesions during endoscopy. ${ }^{5-7,13,14}$ In those studies, a synchronous lesion was defined as a lesion detected within 1 year after the index examination or endoscopic resection. We hypothesized that some of the lesions may have been present at the time of the initial diagnosis, and we therefore, investigated the prevalence of simultaneous lesions prior to the treatment. We found simultaneous lesions in $8.6 \%$ of patients before endoscopic 
Table 3. Characteristics of 12 Patients with Simultaneous Lesions

\begin{tabular}{|c|c|c|c|c|c|c|c|c|c|c|c|c|c|}
\hline \multirow[b]{2}{*}{ No. } & \multirow[b]{2}{*}{$\begin{array}{c}\text { Age, } \\
\text { yr }\end{array}$} & \multirow[b]{2}{*}{ Sex } & \multirow{2}{*}{$\begin{array}{c}\text { Helicobacter } \\
\text { pylori } \\
\text { infection }\end{array}$} & \multirow[b]{2}{*}{$\begin{array}{l}\text { Gastric } \\
\text { atrophy }^{\text {a) }}\end{array}$} & \multicolumn{4}{|c|}{ Primary lesion } & \multicolumn{4}{|c|}{ Simultaneous lesion } & \multirow[b]{2}{*}{ Group $^{c)}$} \\
\hline & & & & & $D x^{b)}$ & Location & $\begin{array}{c}\text { Size, } \\
\mathbf{m m}\end{array}$ & $\mathbf{T x}$ & $D x^{b)}$ & Location & $\begin{array}{c}\text { Size, } \\
\text { mm }\end{array}$ & $\mathbf{T x}$ & \\
\hline 1 & 66 & $\mathrm{M}$ & $\mathrm{Y}$ & $\mathrm{O} 2$ & LGD & MB-LC & 11 & ESD & LGD & Ant-LC & 11 & ESD & 3 \\
\hline 2 & 73 & $\mathrm{~F}$ & $\mathrm{Y}$ & $\mathrm{C} 2$ & $\begin{array}{c}\text { EGC } \\
(\mathrm{W} / \mathrm{D}, \mathrm{m} 2)\end{array}$ & Ant-GC & 34 & ESD & LGD & Angle & 15 & None & 3 \\
\hline 3 & 62 & $\mathrm{M}$ & Y & $\mathrm{C} 2$ & HGD & Angle & 12 & ESD & LGD & MB-LC & 7 & ESD & 2 \\
\hline 4 & 59 & $\mathrm{M}$ & $\mathrm{Y}$ & $\mathrm{O} 1$ & $\begin{array}{c}\text { EGC } \\
(\mathrm{M} / \mathrm{D}, \mathrm{sm} 1)\end{array}$ & Ant-LC & 54 & $\mathrm{ESD}^{\mathrm{d})}$ & LGD & Ant-AW & 35 & ESD & 1 \\
\hline 5 & 59 & M & $\mathrm{Y}$ & $\mathrm{O} 2$ & $\begin{array}{c}\text { EGC } \\
(\mathrm{W} / \mathrm{D}, \mathrm{m} 3)\end{array}$ & Ant-GC & 20 & ESD & LGD & Ant-LC & 7 & ESD & 3 \\
\hline 6 & 74 & M & $\mathrm{N}$ & $\mathrm{C} 2$ & $\begin{array}{c}\text { EGC } \\
(\mathrm{W} / \mathrm{D}, \mathrm{m} 3)\end{array}$ & $\begin{array}{l}\text { Angle } \\
\text {-PW }\end{array}$ & 25 & ESD & $\begin{array}{c}\text { EGC } \\
(\mathrm{W} / \mathrm{D}, \mathrm{m} 2)\end{array}$ & Angle-AW & 15 & ESD & 1 \\
\hline \multirow[t]{2}{*}{7} & 75 & M & $\mathrm{Y}$ & $\mathrm{C} 2$ & $\begin{array}{c}\text { EGC } \\
(\mathrm{M} / \mathrm{D}, \mathrm{m} 2)\end{array}$ & Ant-LC & 13 & ESD & $\begin{array}{c}\text { EGC } \\
(\mathrm{M} / \mathrm{D}, \mathrm{m} 3)\end{array}$ & Angle & 25 & ESD & 3 \\
\hline & & & & & & & & & LGD & Ant-LC & 20 & ESD & 3 \\
\hline 8 & 51 & $\mathrm{~F}$ & $\mathrm{Y}$ & $\mathrm{C} 2$ & LGD & Ant-LC & 8 & APC & LGD & MB-LC & 8 & APC & 3 \\
\hline 9 & 64 & $\mathrm{~F}$ & $\mathrm{Y}$ & $\mathrm{O} 2$ & LGD & MB-LC & 15 & APC & LGD & Ant-LC & 5 & APC & 3 \\
\hline 10 & 78 & M & $\mathrm{Y}$ & $\mathrm{O} 2$ & $\begin{array}{c}\text { EGC } \\
(\mathrm{M} / \mathrm{D}, \mathrm{sm} 1)\end{array}$ & Ant-PW & 37 & $\mathrm{ESD}^{\mathrm{d})}$ & LGD & LB-PW & 15 & ESD & 1 \\
\hline 11 & 59 & M & $\mathrm{Y}$ & $\mathrm{C} 3$ & $\begin{array}{c}\text { EGC } \\
(\mathrm{M} / \mathrm{D}, \mathrm{m} 2)\end{array}$ & Ant-GC & 30 & ESD & $\begin{array}{c}\text { EGC (P/D } \\
\text { with SRC, m2) }\end{array}$ & HB-PW & 14 & ESD & 1 \\
\hline 12 & 77 & $\mathrm{~F}$ & $\mathrm{Y}$ & $\mathrm{O} 2$ & HGD & Ant-LC & 7 & ESD & LGD & Angle-PW & 8 & ESD & 1 \\
\hline
\end{tabular}

Dx, histological diagnosis; Tx, treatment; Y, positive; O, open-type gastritis; LGD, low-grade dysplasia; MB, midbody; LC, lesser curvature; ESD, endoscopic submucosal dissection; C, closed-type gastritis; EGC, early gastric cancer; W/D, well-differentiated; m2, lamina propria; Ant, antrum; GC, greater curvature; HGD, high-grade dysplasia; M/D, moderately differentiated; sm1, submucosal invasion $<500 \mu$ m; AW, anterior wall; m3, muscularis mucosa; N, negative; PW, posterior wall; APC, argon plasma coagulation; LB, lower body; P/D, poorly differentiated; SRC, signet ring cell component.

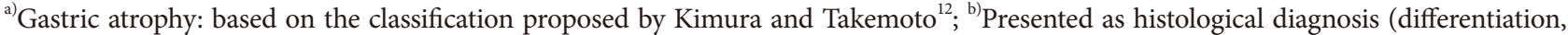
depth); ${ }^{\text {c) }}$ Group 1 (no images of the location of simultaneous lesions were taken), group 2 (images of the location of the simultaneous lesions were available but were not evident at the time of the previous examination), group 3 (images of the simultaneous lesion were available but a biopsy was not performed); ${ }^{\mathrm{d})}$ Noncurative resection of early gastric cancer: subsequent surgery was performed.

resection; these lesions may have led to additional sessions of treatment if they had been disregarded or missed.

Failure to detect simultaneous lesions may be due to several reasons as follows: the lesions are not seen, are seen but not biopsied, are biopsied inadequately, or are interpreted incorrectly by the pathologist. ${ }^{4,710}$ It is noteworthy that almost all missed diagnoses are due to errors by endoscopists. Occasionally, the procedure is performed hastily, without thoroughness, and overlooking the purpose of endoscopy. In the present study, more than half of the cases with missed diagnoses had images of the simultaneous lesion documented in the previous endoscopic examination but they were not biopsied (group 3). Since most of the simultaneous lesions were located in the lower third of the stomach, some of them may have been missed because the endoscopist was concentrating on evaluating the primary lesion or because the evaluation was limited. On the other hand, in more than one-third of the cases there was no documented image of the particular location where the simultaneous lesion was detected (group 1). The majority of these lesions were located in the anterior or posterior wall of the stomach, which is consistent with a report suggesting that the posterior wall of the body is a blind spot. ${ }^{6}$ Endoscopists should always consider the possibility of multifocal or synchronous lesions and should attempt to examine the entire gastric mucosa.

There was one case classified as group 2, which was defined as a simultaneous lesion that was not evident in the earlier images. Group 2 lesions may have been missed because the endoscopist did not recognize the early signs of dysplastic changes, or because the lesion had developed after the index examination. Initially, there may have been only a subtle change that was hardly noticeable at the time of the previous examination. In addition, atrophic or metaplastic changes of the background mucosa may have been a reason for the missed diagnosis. In one study, even advanced gastric cancers were definitely missed and endoscopy performed 3 or 4 months 
Table 4. Comparison of Procedure-Related Factors in Patients with and without Simultaneous Lesions

\begin{tabular}{|c|c|c|c|}
\hline Variable & Without simultaneous lesion & With simultaneous lesion & $p$-value \\
\hline \multicolumn{4}{|l|}{ Previous EGD } \\
\hline Referral center & & & 0.060 \\
\hline Primary care & $46(35.9)$ & $4(33.3)$ & \\
\hline Secondary or tertiary care & $63(49.2)$ & $3(25.0)$ & \\
\hline Healthcare screening & $14(10.9)$ & $4(33.3)$ & \\
\hline Not available & $5(3.9)$ & $1(8.3)$ & \\
\hline Type of image & & & $>0.999$ \\
\hline Printed photo & $5(3.9)$ & 0 & \\
\hline Digital image & $123(96.1)$ & $12(100.0)$ & \\
\hline Quality of image & & & 0.603 \\
\hline Poor & $14(10.9)$ & 0 & \\
\hline Fair & $77(60.2)$ & $9(75.0)$ & \\
\hline Good & $37(28.9)$ & $3(25.0)$ & \\
\hline Total no. of images & $30(22-39)$ & $27(20-30)$ & 0.233 \\
\hline No. of valid images & $18(12-24)$ & $17(11-19)$ & 0.486 \\
\hline Procedure time, min & $4.95(3.23-6.77)$ & $3.75(2.77-6.60)$ & 0.392 \\
\hline \multicolumn{4}{|l|}{ Repeat EGD } \\
\hline Total no. of images & $67(57-78)$ & $59(56-87)$ & 0.500 \\
\hline No. of valid images & $39(32-45)$ & $41(36-44)$ & 0.587 \\
\hline Procedure time, min & $6.67(4.85-9.02)$ & $6.32(5.15-9.08)$ & 0.994 \\
\hline Interval, day & $16(10-27)$ & $16(10-23)$ & 0.783 \\
\hline
\end{tabular}

Values are presented as number (\%) or median (interquartile range).

EGD, esophagogastroduodenoscopy.

Table 5. Comparison between Previous and Repeat Esophagogastroduodenoscopy

\begin{tabular}{|c|c|c|c|c|c|c|}
\hline \multirow[t]{2}{*}{ Variable } & \multicolumn{3}{|c|}{ Without simultaneous lesion } & \multicolumn{3}{|c|}{ With simultaneous lesion } \\
\hline & Previous EGD & Repeat EGD & $p$-value & Previous EGD & Repeat EGD & $p$-value \\
\hline Total no. of images & $30(22-39)$ & $67(57-78)$ & $<0.001$ & $27(20-30)$ & $59(56-87)$ & 0.002 \\
\hline No. of valid images & $18(12-24)$ & $39(32-45)$ & $<0.001$ & $17(11-19)$ & $41(36-44)$ & 0.002 \\
\hline Procedure time, min & $4.95(3.23-6.77)$ & $6.67(4.85-9.02)$ & $<0.001$ & $3.75(2.77-6.60)$ & $6.32(5.15-9.08)$ & 0.012 \\
\hline \multicolumn{7}{|c|}{ Difference between previous and repeat EGD } \\
\hline Total no. of images & \multicolumn{2}{|c|}{$39(21-50)$} & & \multicolumn{2}{|c|}{$43(27-62)$} & $0.253^{\mathrm{a})}$ \\
\hline No. of valid images & \multicolumn{2}{|c|}{$21(13-29)$} & & \multicolumn{2}{|c|}{$26(15-32)$} & $0.239^{\mathrm{a})}$ \\
\hline Procedure time, min & \multicolumn{2}{|c|}{$1.68(-0.71$ to 3.73$)$} & & \multicolumn{2}{|c|}{$2.22(0.40-7.12)$} & $0.330^{\mathrm{a})}$ \\
\hline
\end{tabular}

Data represent median (interquartile range).

EGD, esophagogastroduodenoscopy.

${ }^{a)} p$-value: comparison between patients without and with simultaneous lesion.

before the final diagnosis did not reveal any abnormalities, supporting the possibility of missed diagnosis rather than rapidly growing cancer. ${ }^{10}$ Meticulous endoscopic examination is important, and additional techniques such as narrow band imaging or chromoendoscopy might be useful for enhancing diagnostic performance. ${ }^{15-17}$
Although the importance of implementing a process for maintaining and enhancing the quality of endoscopy has been emphasized in clinical practice, there have been no clearly documented quality indicators regarding esophagogastroduodenoscopy. Recently proposed quality indicators include measures of process and outcome, and recommend photodoc- 
umentation of important anatomic landmarks and pathologic findings during endoscopic examination. ${ }^{18}$ Endoscopic images reflect the quality and completeness of endoscopic evaluation and provide information about pathology that facilitates consultation with other physicians. Although the evidence is limited, it may be worthwhile to consider repeat endoscopy to ultimately reach treatment decisions, particularly if previously obtained information is suboptimal or equivocal.

The recommendations also emphasize that the number of procedures performed in training should not be used to define competence, but that objective measurement of performance is essential. ${ }^{18}$ According to one report, procedure times of more than 10 minutes were more frequent when a simultaneous lesion was detected, and the probability of detecting synchronous neoplasms decreased by $6.9 \%$ as the duration of endoscopic examination decreased by 1 minute. ${ }^{7}$ However, in our study neither the duration of endoscopic examination nor the absolute differences in the procedure times between previous and repeat procedures were significantly different. Hence, prolonging a procedure does not always guarantee a higher quality of endoscopic examination. A more appropriate quality indicator which can reflect the completeness of the examination is needed.

Our study has several limitations. First, because our analyses were retrospective and based on a database from a single physician, selection bias and referral bias cannot be excluded. Second, we could not evaluate operator-dependent factors, including the level of experience, and this might have influenced the detection rate. In addition, the duration of endoscopic examination was shorter than that of a previous study, ${ }^{7}$ and the possibility of missed diagnosis even after several sessions of repeat endoscopy could not be excluded. Third, we could not calculate the cost-effectiveness of repeated endoscopic examination. Although the detection of simultaneous gastric neoplasms before endoscopic resection enables the treatment of all the lesions at a single time, the cost and benefit of such treatment is uncertain. The cost and risk of repeat endoscopy with biopsy may outweigh the potential benefits of additional information about the primary lesion, which only rarely modifies the treatment strategy. ${ }^{19}$ In addition, not only incorrect endoscopic resection but also the presence of simultaneous lesions contribute to the increase in cost. In our study, three cases of early gastric cancers, including undifferentiated cancers located in the upper third of the stomach, were detected by repeat endoscopy and may have led to a change in treatment strategy. Another limitation is that a relatively small number of patients were included in the analysis. The prevalence of simultaneous lesions was $8.6 \%$ in our study, and this may have been an underestimate.

In conclusion, lesions disregarded or unnoticed during the initial endoscopic examination were the main reason for missed diagnosis of simultaneous lesions. Meticulous and complete evaluation of the entire gastric mucosa, rather than of specific key areas, is mandatory for detecting both the index lesion and any simultaneous lesions. Repeat endoscopy may provide additional information before definitive treatment regardless of the quality of the previously obtained images.

Conflicts of Interest

The authors have no financial conflicts of interest.

\section{REFERENCES}

1. Ahn JY, Jung HY, Choi KD, et al. Endoscopic and oncologic outcomes after endoscopic resection for early gastric cancer: 1370 cases of absolute and extended indications. Gastrointest Endosc 2011;74:485-493.

2. Choi MK, Kim GH, Park DY, et al. Long-term outcomes of endoscopic submucosal dissection for early gastric cancer: a single-center experience. Surg Endosc 2013;27:4250-4258.

3. Gong EJ, Ahn JY, Jung HY, et al. Risk factors and clinical outcomes of gastric cancer identified by screening endoscopy: a case-control study. J Gastroenterol Hepatol 2014;29:301-309.

4. Voutilainen ME, Juhola MT. Evaluation of the diagnostic accuracy of gastroscopy to detect gastric tumours: clinicopathological features and prognosis of patients with gastric cancer missed on endoscopy. Eur J Gastroenterol Hepatol 2005;17:1345-1349.

5. Lee HL, Eun CS, Lee OY, et al. When do we miss synchronous gastric neoplasms with endoscopy? Gastrointest Endosc 2010;71:1159-1165.

6. Kim HH, Cho EJ, Noh E, et al. Missed synchronous gastric neoplasm with endoscopic submucosal dissection for gastric neoplasm: experience in our hospital. Dig Endosc 2013;25:32-38.

7. Kim HH, Kim JH, Kim GH, Choi MG, Jee SR, Song GA. Causes of missed synchronous gastric epithelial neoplasms with endoscopic submucosal dissection: a multicenter study. Scand J Gastroenterol 2013;48:1339-1346.

8. Yoo JH, Shin SJ, Lee KM, et al. How can we predict the presence of missed synchronous lesions after endoscopic submucosal dissection for early gastric cancers or gastric adenomas? J Clin Gastroenterol 2013;47:e17-e22.

9. Hosokawa O, Watanabe K, Hatorri M, Douden K, Hayashi H, Kaizaki $\mathrm{Y}$. Detection of gastric cancer by repeat endoscopy within a short time after negative examination. Endoscopy 2001;33:301-305.

10. Yalamarthi S, Witherspoon P, McCole D, Auld CD. Missed diagnoses in patients with upper gastrointestinal cancers. Endoscopy 2004;36:874879.

11. Japanese Gastric Cancer Association. Japanese classification of gastric carcinoma: 3rd English edition. Gastric Cancer 2011;14:101-112.

12. Kimura K, Takemoto T. An endoscopic recognition of the atrophic border and its significance in chronic gastritis. Endoscopy 1969;1:87-97.

13. Sung IK, Kim YC, Yun JW, et al. Characteristics of advanced gastric cancer undetected on gastroscopy. Korean J Gastroenterol 2011;57:288293.

14. Ren W, Yu J, Zhang ZM, Song YK, Li YH, Wang L. Missed diagnosis of early gastric cancer or high-grade intraepithelial neoplasia. World J Gastroenterol 2013;19:2092-2096.

15. Kato M, Kaise M, Yonezawa J, et al. Magnifying endoscopy with narrow-band imaging achieves superior accuracy in the differential diagnosis of superficial gastric lesions identified with white-light endoscopy: a prospective study. Gastrointest Endosc 2010;72:523-529.

16. Zhang Q, Wang F, Chen ZY, et al. Comparison of the diagnostic efficacy of white light endoscopy and magnifying endoscopy with narrow 
band imaging for early gastric cancer: a meta-analysis. Gastric Cancer 2016;19:543-552.

17. Zhao Z, Yin Z, Wang S, et al. Meta-analysis: the diagnostic efficacy of chromoendoscopy for early gastric cancer and premalignant gastric lesions. J Gastroenterol Hepatol 2016 Feb 9 [Epub]. https://doi.org/10.1111/ jgh.13313.
18. Rizk MK, Sawhney MS, Cohen J, et al. Quality indicators common to all GI endoscopic procedures. Gastrointest Endosc 2015;81:3-16.

19. Yang MJ, Shin SJ, Lee KS, et al. Non-neoplastic pathology results after endoscopic submucosal dissection for gastric epithelial dysplasia or early gastric cancer. Endoscopy 2015;47:598-604. 